\title{
EL POEMA EN PROSA Y EL PRINCIPIO ANTIMÉTRICO
}

Miguel Á. MÁrquez

Universidad de Huelva

\section{RESUMEN}

Los tratados teóricos, desde la Retórica de Aristóteles hasta los estudios comtemporáneos sobre el poema en prosa, han prescrito siempre que se evite el ritmo del verso en la prosa. Esta prohibición se conoce con el nombre de principio antimétrico. Sin embargo, la literatura en prosa, desde Isócrates a Borges, ha utilizado los recursos rítmicos propios del sistema de versificación coetáneo, junto con los procedimientos característico del ritmo prosario.

\section{INTRODUCCIÓN}

Luis Cernuda escribió en 1959 uno de los primeros ensayos sobre el poema en prosa español (Cernuda, 1975), donde postulaba que habría que buscar su origen en Francia, en las traducciones de cantos extranjeros; A. Bertrand con su Gaspard de la Nuit (1842) representaría la primera fase de la evolución del género, a la que seguirían los $P e$ tits Poèmes en Prose (1869) de Baudelaire y Les Illuminations (1886) de Rimbaud (Cernuda, 1975: 985). Según Cernuda, en España, Bécquer inauguraría nuestro poema en prosa, al mismo tiempo que renovaría el verso español haciéndolo más flexible y convirtiéndolo en un instrumento más adecuado a los propósitos del poeta:

Así, paralelamente a como aproxima el verso a la prosa, trata también de acercar la prosa al verso, no para escribir una prosa poética, sino para hacer de la prosa un instrumento efectivo de la poesía (Cernuda, 1975: 987). 
Cernuda insistía en que debía tenerse en cuenta la intencionalidad del poeta a la hora de calificar un texto como poema en prosa. La comunidad de verso y prosa, fue puesta de manifiesto por Cernuda comentando «La Creación» (Leyendas):

Porque en efecto «La Creación» nos aparece como una suerte de poesía en prosa, dividida como está la composición en trozos de prosa de extensión no muy desigual, precedido cada uno de números romanos, para indicar su equivalencia con las estrofas en verso [...]. Léase toda la estrofa primera, y tal vez se perciba que ahí, en efecto, era intención de Bécquer utilizar, a excepción del verso, todos los recursos literarios de la poesía (Cernuda, 1975: 988-989).

Cernuda detectó en algunas de la Leyendas becquerianas una similitud del párrafo con la estrofa; admitía la comunidad de acento, ritmo y expresión de esa prosa y la poesía, pero excluía la posibilidad de que el poema en prosa pudiera segmentarse rítmicamente como el verso'. Esta posición crítica de Cernuda no era otra cosa que la formulación contemporánea del principio antimétrico, base teórica que establecieron los primeros preceptistas para el desarrollo de la prosa rítmica.

Este artículo pretende demostrar que los autores de poemas en prosa con frecuencia se apartan del principio antimétrico, considerado requisito necesario por los teóricos, que pretenden deslindar así la prosa poética del sistema de versificación. Los datos empíricos resultan muy relevantes y para la distinción de verso y prosa, puesto que parecen corroborar la idea de que no son recursos formales o rítmicos los que distinguen verso y prosa, ni cuestiones de cantidad o regularidad, sino que es el patrón métrico, el ritmo progresivo y la disposición gráfica los factores decisivos para clasificar un texto como prosa o verso (Domínguez Caparrós, 1988a: 21-30).

\section{EL PRINCIPIO ANTIMÉTRICO}

El principio antimétrico es uno de los axiomas más extendidos dentro la teoría retórica del oratorius numerus; prescribe la evitación de los metros poéticos en la prosa rítmica. La primera referencia a la teoría del numerus se encuentra en la Retórica de Aristóteles, donde presenta un marcado carácter preceptivo. El desarrollo del numerus tropieza con una primera gran dificultad en el hecho de que se debe introducir el ritmo en la prosa sin que se convierta en verso (Arist. $R$ h. 3.8.1):

La forma de la composición en prosa no debe ser en verso pero tampoco carente de ritmo, ya que lo primero no resulta convincente (pues parece artificial), además de que distrae la atención, pues hace que se esté pendiente de cuándo volverá a aparecer el elemento recurrente [...]. Pero la forma carente de ritmo es indefinida, y debe ser definida, aunque no sea

\footnotetext{
' Cernuda llama también la atención sobre la afinidad de un pasaje de la «El Caudillo de las Manos Rojas» con una de las Rimas; la imposibilidad de establecer la cronología relativa entre esas dos composiciones, impide que Cernuda determine si se trata de un eco o un anticipo. El hecho en sí es interesante y Cernuda nos recuerda que «Baudelaire, en sus Petits Poèmes en Prose, repite como poemas en prosa algunas de sus composiciones en verso de Les Fleurs du Mal, anteriores a aquéllos (Cernuda, 1975: 90)»
} 
en verso, ya que lo indefinido es desagradable y difícil de entender. Ahora bien, es por el número por lo que todo adquiere definición, y el número de la forma de la elocución es el ritmo, del que los metros no son sino apartados. Por ello el discurso debe tener ritmo, pero no metro, pues sería un poema, así que será un ritmo no absolutamente riguroso, y será así si no pasa de un cierto límite ${ }^{2}$.

La naturaleza preceptiva del principio antimétrico es patente en Aristóteles, quien después de referirse al ritmo heroico (dactílico), al yambo y al troqueo, prescribe explícitamente el uso del peón en la oratoria (Arist. $R$ h. 3.8.1):

Ahora bien, los demás ritmos deben descartarse por las razones expuestas y porque son métricos, pero hay que aceptar el peón, pues es el único de los ritmos mencionados que no es métrico, de modo que también pasa más inadvertido.

Aristóteles recomienda el uso del peón porque este pie no forma metros poéticos ( $\mathrm{Ra}$ cionero, 1990: 520 n.135). Según Aristóteles, el peón es el ritmo más adecuado a la oratoria porque hace posible la entrada del ritmo y evita, al mismo tiempo, la forma poética ${ }^{3}$.

A pesar de que Aristóteles en su Retórica nos ofrece el más temprano tratamiento sistemático del ritmo de la prosa, debemos considerar que es Cicerón el primer autor que lleva a cabo una verdadera reflexión teórica sobre el ritmo de la prosa en relación con el ritmo del verso. Cicerón no duda de la existencia de «cierto» ritmo en la prosa, basándose en lo que nos indica nuestro sentido auditivo, y eso es así aunque no podamos determinar sus reglas. El principal problema teórico que se plantea Cicerón es el de investigar si el ritmo de la prosa es el mismo que el del verso; en esta parcela, Cicerón es claro (Cic. Orat. 188 y 190):

Lo que hay que analizar a continuación es si ese ritmo es el mismo de la poesía o es un ritmo de otro tipo. Pues bien no hay ningún ritmo diferente del poético.

Quede, pues, reconocido que también en prosa hay ritmo y que los ritmos de la prosa son los mismos que los de la poesía.

Después de admitir la comunidad de ritmo, Cicerón intenta distiguir verso y prosa por su cumplimiento del ritmo, al que la prosa se somete en alguna medida pero sin llegar a la «esclavitud rítmica» del verso, lo que la diferencia del lenguaje coloquial (Cic. Orat. 195). Profundiza en su reflexión sobre el ritmo de la prosa y nos dice que debe quedar oculto (Cic. Orat. 197); especialmente llama la atención su agudeza para resaltar que

${ }^{2}$ Los pasajes de la Retórica aristotélica se citan siguiendo la traducción de A. Bernabé (1998).

${ }^{3}$ La relación entre el principio antimétrico y la recomendación de utilizar el peón y evitar los otros pies es recogida también por Cicerón (Cic. Orat. 194): «Efectivamente el yambo y el dáctilo se encuentran mucho en verso, de manera que, si en la prosa es, en efecto, otra cosa y nada más contrario al verso, debemos evitar en ella el uso continuado de estos pies; la prosa es, en efecto, otra cosa y nada más contrario al verso que ella; el peón, sin embargo, en absoluto es un pie apto para el verso, por lo que la prosa lo acepta mejor»; todos los paisajes de El Orador de Cicerón son citados según la traducción de Sánchez Salor (1991). Véase igualmente la prescripción de utilizar en la prosa el peón y evitar el metro heorico en Demetrio (Eloc. 38-42). 
en el ritmo de la prosa la imprevisión y la ruptura de expectativas son necesarias (Cic. Orat. 198). Pero en definitiva, después de reconocer la cercanía de prosa y verso, Cicerón vuelve a enunciar el principio antimétrico (Cic. Orat. 201):

Y no sólo en lo que se refiere al ritmo, sino también en lo que se refiere a todos los demás adornos oratorios, aunque procedemos de la misma forma que los poetas, en la prosa, sin embargo, evitamos la similitud con la poesía.

El principio antimétrico reaparecerá en otras obras de Cicerón (Cic. de Orat. 3.184) y en Quintiliano (Quint. Inst. 9.5.4), de modo que la posición normativa, tendente a separar radicalmente la compositio de la prosa del sistema de versificación, terminó siendo casi un dogma general. Si el sistema retórico clásico considera un defecto el uso de los metros poéticos, no tolera de ninguna manera los metricismos, es decir, la percepción de versos completos o hemistiquios en la prosa, sobre todo si se halla un final de verso como cláusula o, a la inversa, el principio de verso al principio de frase. En este sentido, Lausberg ( $\$ 981)$ señala que Marciano Capela reprochó a Cicerón el empleo de un endecasílabo: súcessít tibi Lúciús Metéllus (Mart. Cap. 34, 517) ${ }^{4}$.

\section{RUPTURAS DEL PRINCIPIO ANTIMÉTRICO EN LA PROSA CLÁSICA}

Sin embargo, a pesar de la artificial separación de prosa y verso que impone la tradición retórica, podemos sospechar que el desarrollo de la prosa artística fue un proceso más cercano a la versificación de lo que postulaban los tratadistas, desde Aristóteles a Quintiliano. Resulta extremadamente interesante comprobar que, mientras Aristóteles rechaza el yambo y el troqueo como ritmos para la oratoria por su carácter métrico y pretende que la prosa se aleje de la poesía utilizando un pie sin tradición poética (peón), Isócrates aconseja el uso (Isoc. Fr. 27 Radermacher) y utiliza de hecho los pies en los que se basa la poesía dramática (tragedia y comedia), el género más difundido en su época. La poesía dramática y la oratoria de Isócrates utilizan el yambo y el troqueo, porque ambas formas literarias buscan asemejarse a la lengua conversacional sin renunciar al ritmo. Sabemos por Cicerón (Cic. Orat. 191) que el yambo no sólo aparece habitualmente en la obra de Isócrates sino también que es un pie muy frecuente en toda la prosa griega y latina.

Del mismo modo, Quintiliano, coherente con el principio antimétrico, excluía la cláusula heroica para que no se oyera el final del período como un final de hexámetro. Pero esta cláusula es abundantísima en las obras de Bruto, Salustio y Tito Livio; Núñez González (1988) ha demostrado que es un rasgo del sistema de cláusulas de los oradores aticistas y de los historiadores.

Dionisio de Halicarnaso en Sobre la composición literaria (D.H. Comp.) profundiza la reflexión sobre las relaciones de prosa y verso con respecto a la Retórica aristotélica y la obra de Cicerón. Parte de la teoría de que la distinción entre poesía y prosa es cuestión de grado y no de cualidad (D.H. Comp. XI 58). Pero es en la sección V de su

\footnotetext{
${ }^{4}$ Igualmente Laustrirg. cita a J.P. Sartre: «Ne doit-on pas, monsieur, éviter soigneusemente les alexandrins dans la prose?» (La Nausée, 1938, p. 47)
} 
tratado (capítulos XXV y XXVI), donde Dionisio descubre la base sobre la que se relacionan la mejor poesía y la mejor prosa. Dionisio parece seguir el principio antimétrico cuando afirma (D.H. Comp. 25, 9-10):

Como decía, un texto en prosa no puede asemejarse a la épica o a la lírica si no contiene algunos metros y ritmos entremezclados secretamente. Sin embargo, no conviene que parezca métrico y rítmico (pues será entonces un poema épico o lírico y se desprenderá absolutamente de su propio carácter), sino que basta sólo con que parezca eurítmico y bien medido. Pues así sería poético sin ser un poema épico y melódico sin ser poema lírico ${ }^{5}$.

Pero su análisis va más allá del enunciado aristotélico o ciceroniano, porque se plantea cuál es la diferencia entre el lenguaje eurítmico de la prosa y el ritmo del verso (D.H. Comp. 25.11):

La poesía contiene metros iguales; conserva ritmos fijos; se desarrolla en líneas, períodos o estrofas con las mismas formas; utiliza después los mismos ritmos y metros en las líneas, períodos y estrofas sucesivos; y repitiendo eso, es rítmica y métrica. Tal forma de dicción recibe los nombres de poesía épica y poesía lírica. La prosa, a su vez, contiene metros alejados y ritmos irregulares; no muestra secuencia, afinidad ni responsión entre ellos.

La posición de Dionisio es muy clara: metros y ritmos en la prosa aparecen dispersos, no de la manera continua en la que aparecen en el verso; la falta de secuencia va acompañada por la irregularidad y la falta de responsión. Sin embargo, no debe pasarnos desapercibida una diferencia esencial entre Aristóteles o Cicerón y Dionisio, ya señalada por Breitenbach: Aristóteles y Cicerón pretenden establecer las diferencias de estilo entre prosa y poesía, mientras que Dionisio llama nuestra antención sobre su semejanza (Breitenbach, 1911: 175). Dionisio parte de que la prosa es semejante a un poema épico o lírico, de la misma manera que un poema es casi igual a la mejor prosa (D.H. Comp. 25.1) y ejemplifica su idea con discursos de Demóstenes. Para resaltar la semejanza de prosa y verso, Dionisio renuncia a tratar las cláusulas y analiza los metricismos de períodos enteros, planteándose si debe considerarse como un fenómeno espontáneo e involuntario o es producto del arte (D.H. Comp. 25.17):

Se dirá tal vez que eso se debe no a una práctica voluntaria sino a la espontaneidad, pues la naturaleza improvisa muchos metros. Pongamos que sea verdad. Pero el colon que está unido a ése, si se deshace la segunda elisión que uniéndolo al tercer colon hace que no lo podamos distinguir, será un pentámetro elegíaco completo.

Dionisio continúa minuciosamente su análisis, señalando muchos versos en el mismo pasaje de Demóstenes. La conclusión parece clara: Demóstenes introduce voluntaria, artística y sistemáticamente versos en su prosa.

${ }^{5}$ Los paisajes de Sobre la composición literaria de Dionisio de Halicarnaso se citas siguiendo mi traducción (Galán Vioque-Márquez: 2001). 


\section{EL PRINCIPIO ANTIMÉTRICO EN LOS ESTUDIOS SOBRE EL POEMA EN PROSA}

Antes de que Cernuda enunciara su formulación personal del principio antimétrico, Díaz Plaja había sugerido de una manera menos precisa esta misma idea; véanse las palabras iniciales de su monografía sobre el poema en prosa en España: «Denominamos 'poema en prosa' toda entidad literaria que se proponga alcanzar el clima espiritual y la unidad estética del poema sin utilizar los procedimientos privativos del verso» (Díaz Plaja, 1956: 3). Más adelante repite su posición teórica: «Analizamos, pues, el más importante fenómeno de la literatura de nuestro tiempo: el de la creación de un lenguaje capaz de alcanzar - sin los elementos propios del verso- la tensión y el 'el clima' propios de la poesía” (Díaz Plaja, 1956: 25). Creo que legitimamente podemos deducir que para Díaz Plaja la versificación se incluye entre «los procedimientos privativos del verso» y «los elementos propios del verso», como veremos en el siguiente parágrafo $(\S 5)$.

Los estudios sobre el poema en prosa se han desarrollado desde los tempranos ensayos de Díaz Plaja y Cernuda. Así, Aullón de Haro establece que el poema en prosa se crea en el Romanticismo ${ }^{6}$, como un rasgo de la modernidad: «Es curioso cómo la modernidad ha actuado de catalizador, provocando una aproximación bipolar resultado de la cual es la abundante poeticidad de la prosa contemporánea $[. .$.$] y un frecuente pro-$ saísmo [de la poesía]» (Aullón de Haro, 1979: 109 n.1). Aullón de Haro se distancia de Díaz Plaja y de Cernuda al considerar el poema en prosa no una creación francesa sino germánica. Sin embargo, admite la idea preestablecida de que el poema en prosa puede tener los mismos componentes que el poema en verso, excepto su «organización pausal» (Aullón de Haro, 1979: 110). Nos encontramos pues ante otra enunciación del principio antimétrico de la retórica.

Para Aullón de Haro cuatro son los autores que determinan la génesis del poema en prosa en lengua española: José Somoza, Pablo Piferrer, Enrique Gil y Carrasco y Gustavo Adolfo Bécquer (Aullón de Haro, 1979: 115). Además anota que en El Señor de Bembibre se hallan fragmentos de prosa poética que lindan con el poema en prosa, especialmente en las descripciones poéticas de paisajes: junto a las anáforas y otros recursos rítmicos, llama poderosamente la atención el frecuente uso de la rima (Aullón de Haro, 1979: 125). Después de Bécquer, el Modernismo impulsó definitivamente el desarrollo del poema en prosa tras la publicación de Azul (1888). Ahora bien, la gran obra de este género será Poemas en prosa; Darío compone «un libro enteramente concebido mediante poemas en prosa. La idea, como es palpable, procedía de Francia» (Aullón de Haro, 1979: 128) ${ }^{7}$.

Por su parte, Valender (1984) admite el origen romántico del poema en prosa y retoma el espíritu del principio antimétrico:

${ }^{6}$ Cf. Diaz Plaja (1956: 9-10)

${ }^{7}$ Gil de Biedma perspicazmente vio que el uso de la prosa como fines poéticos es un fenómeno que afecta a todos los grandes escritores de la época, como Unamuno, Azorín o Baroja. Después de Juan Ramón Jimenez, el surrealismo dejó tres poemarios en prosa: La flor de california de J.M. Hinojosa, Oscuro dominio de J.Larrea y Pasión de la tierra de V. Aleixandre. Superado el surrealismo, Cernuda compuso Ocnos y Variaciones sobre un tema mexicano (Aullón de Haro, 1979: 131-133). 
«El verso se caracterizaba por la rima y el metro; todo lo demás, por definición, era prosa. Los románticos acabaron para siempre con esta distinción. Concibiendo la poesía como expresión del espíritu de la naturaleza [...] atacaron la versificación tradicional. [...] Puesto que el ritmo de la frase se hizo más importante que la versificación silábica, la prosa fue reconocida como medio de expresión igualmente aceptable para el poeta. Por tanto, lo que se vio, en términos generales, fue una paulatina convergencia de verso y prosa» (Valender, 1984: 13).

En España, Valender considera a Bécquer un caso excepcional del siglo XIX por su interés en el poema en prosa. Sin embargo, recogiendo una idea de Cernuda, achaca a las Leyendas el hecho de el elemento narrativo impida la consecución de un auténtico poema en prosa (Valender, 1984: 18).

En su reciente monografía sobre el poema en prosa, Utrera (1999) ha estudiado minuciosamente la evolución del poema en prosa en Francia y dedica un capítulo de su trabajo al poema en prosa de Rubén Darío. Para Utrera, el Modernismo acerca definitivamente la prosa y la poesía como había anticipado Bécquer y el Romanticismo. Este acercamiento consiste en desdibujar los límites tradicionales que separan «ambos géneros» (Utrera, 1999: 210-211), siguiendo a Mallarmé y, se puede añadir, Whitman. Utrera advierte que, si desde el Romanticismo la literatura busca la unión con la música y la pintura, no debe extrañarnos «que se aproximen hasta confundirse la prosa y el verso» (Utrera, 1999: 222). Con Azul, obra en la que se combinan prosa y verso, Darío muestra su voluntad de equiparar ambas formas de expresión y de elevar la prosa a la altura del verso (Utrera, 1999: 223). Utrera postula que Bertrand y Baudelaire, en tanto creadores del poema en prosa moderno, «pretendían, explícitamente este último, dar a la prosa la nobleza de la poesía en verso, pero manteniendo su autonomía, es decir, hacer poesía no con los medios de recurrencia regular del verso, sino con el ritmo más libre y heterogéneo y los recursos de la prosa» (Utrera, 1999: 190-191). Su posición, de alguna manera, responde al modelo teórico que encuentra en el principio antimétrico la piedra angular de la prosa artística ${ }^{8}$.

\section{Metros POÉtico EN El POEMA EN PROSA}

Como vimos en el parágrafo $\$ 3$, la prosa artística de la Antigüedad recurrió a los metros que se utilizaban en la versificación coetánea más extendida (el troqueo y el yambo de la poesía dramática y el dáctilo de la épica) e incluso a verdaderos metricismos (versos y hemistiquios completos en los textos en prosa). Esta práctica que se remonta a los discursos de Isócrates tuvo su continuación en las obras de Demóstenes - como demostró Dionisio de Halicarnaso en La composición literaria - y en la prosa de los historiadores y oradores aticistas de Roma. La introducción de metros y versos completos

${ }^{8}$ Ya en las páginas iniciales de su monografía, Utrera señalaba que Baudelaire buscaba alejarse de las modalidades de la prosa ritmada y rimada (Utrera, 1999: 22). Naturalmente Utrera hace referencia a diversos estudios que han señalado metricismos en la prosa de carácter liríco (como las Noches lúgubres de Cadalso), aunque su posición es de reserva: «Hay que advertir, sin embargo, que la búsqueda de versos aislados en la prosa no siempre es un camino útil y adecuado para justificar una obra como lírica.[...] Estos metricismos deben tomarse, pues. con cautela» (Utela, 1999: 37). 
en la prosa contradecía el principio antimétrico preceptuado por todos los teóricos desde Aristóteles a Quintiliano.

Con el desarrollo del poema en prosa contemporáneo, podemos observar un fenómeno parecido: mientras que los críticos y teóricos enuncian de una manera u otra el principio antimétrico tradicional (Díaz, Plaja, Cernuda, Aullón de Haro, Valender, Utrera), unos pocos ejemplos - a los que la crítica ha aplicado dicho principio - bastarán para demostrar que es fácil detectar el sistema de versificación como recurso rítmico propio del poema en prosa.

Coherente con su posición teórica de exclusión de «los procedimientos privativos del verso» en la constitución rítmica del poema en prosa, Díaz Plaja analiza «El caudillo de las Manos Rojas» de Bécquer y, de una manera explícita, postula: «No es posible hablar de un ritmo en sentido riguroso, y sí aproximadamente [de] una cierta cadencia acentual, no reducible a número constante» (Díaz Plaja, 1956: 28). Sin embargo, si consideramos el primer fragmento citado:

Ha desaparecido el sol tras las cimas del Jabwi y la sombra de esta montaña envuelve con un velo de crespón a la perla de las ciudades de Osira, a la gentil Kattak, que duerme a su pies, entre los bosques de canela y sicomoros semejante a una paloma que descansa sobre un nido de flores.

observamos que el ritmo endecasilábico, con predominio de eneasílabos, sustenta su ritmo:

$\begin{array}{ll}\text { Ha desaparecido el sol } & 9 \\ \text { tras las cimas del Jabwi } & 7 \\ \text { y la sombra de esta montaña } & 9 \\ \text { envuelve con un velo de crespón } & 11 \\ \text { a la perla de las ciudades } & 9 \\ \text { de Osira, a la gentil Kattak, } & 9 \\ \text { que duerme a su pies, } & 7 \\ \text { entre los bosques de canela } & 9 \\ \text { y sicomoros semejante } & 9 \\ \text { a una paloma que descansa } & 9 \\ \text { sobre un nido de flores. } & 7\end{array}$

De una manera similar, Aullón de Haro analiza la composición titulada «Elegía» de José Somoza, uno de los cuatro autores que generarían el poema en prosa en español (Aullón de Haro, 1979: 110); comenta sus diversos recursos rítmicos, pero llama la atención que no se mencionen los abudantes metricismos que recorren «Elegía», desde sus dos endecasílabos iniciales:

¿Cuándo será que vuelva a vuestras sombras, 11 robles antiguos de La Pesqueruela?

hasta la serie de heptasílabos cerrada por un eneasílabo con la que termina este poema en prosa: 
Mezclarse mis huesos $\quad 7$

con los de mis mayores; $\quad 7$

ni encima de mi tumba, $\quad 7$

podrá ningún mortal 7

poner la marca de la ignomia. 9

Ejemplos como los anteriores apuntan a que los creadores del poema en prosa espanol utilizaron como un recurso más la versificación coetánea (aunque la crítica, coherente con el principio antimétrico, no le otorgue a este fenómeno la importancia que merece). Ahora bien, «La canción del oro» de Rubén Darío $(A z u l)$ presenta un interés especial, porque al final de la composición el poeta-mendigo entona un «himno en prosa o letanía» al oro. Aparentemente el ritmo de este pasaje se basa en la «acumulación basada en el símil y en la repetición de estructuras paralelísticas con carácter enumerativo" (Utrera, 1999: 224) ${ }^{10}$. Así pues, el ritmo prosario de «La canción del oro» no se diferenciaría en nada de los recursos habituales de la prosa paralelística, antitética y enumerativa. Sin embargo, quizá merezca la pena considerar algunos párrafos (o estrofas) de este «Canción del oro», para ver si, además de la rima y los recursos de pensamiento, se encuentran otros elementos rítmicos comunes con el verso. Por ejemplo, en el segundo párrafo, se tiene la impresión de oír un ritmo semejante al de la versificación de cláusulas:

Cantémos el óro, que náce del viéntre fecúndo de la madre tierra; inménso tesóro, léche rúbia de ésa úbre gígantésca.

La serie de cinco anfíbracos es evidente en la primera frase; la segunda comienza igualmente por dos anfíbracos, a los que siguen cinco troqueos; Domínguez Caparrós ha señalado que uno de los ejemplos canónicos de la versificación de cláusulas es la Marcha triunfal (1895) de Rubén Darío, «con versos formados por la unión de cláusulas trisílabas de ritmo anfibráquico» (Domínguez Caparrós, 1999: 194) ${ }^{11}$. En el cuarto párrafo, hallamos unos metricismos muy marcados en los dos períodos, se trata de dos series de octosílabos incluso con rima:

Cantemos el oro, porque de él se hacen las tiaras de los pontífices, las coronas de los reyes y los cetros imperiales; y porque se derrama por los mantos como un fuego sólido, e inunda las capas de los arzobispos, y refulge en los altares y sostiene al Dios eterno en las custodias radiantes.

${ }^{9}$ Según la calificación de Valera (cf. Utrera, 1999: 224).

10 «La repetición anafórica de "Cantemos el oro" que inicia la casi totalidad de los breves párrafos del himno y que aparece también como frase aislada al principio y al final del canto, dándole una estructura circular, el ejemplo de abundantes paralelismos basados en frases causales y en series de oraciones yuxtapuestas que funcionan como aposiciones explicativas, las continuas invocaciones, enumeraciones y juegos sinetésicos, junto a otros recursos estilísticos, otorgan al discurso del mendigo un poema escrito en versículos, dadas las ocasionales reiteraciones silábicas y el ejemplo de las rimas internas consonantes y asonantes» (Utrera, 1999: 227).

1 También Domínguez Caparrós nos recuerda que Belmás (1960) consideró «como poema en hexámetros un parlamento en prosa que Rubén Darío pone en boca de Lucio Varo, en su novela arqueologica El hombre de oro, y que versifica con el título de Canto de Varo a Roma» (Domínguez Caparrós, 1999: 203). 


$\begin{array}{ll}\text { las tiaras de los pontífices } & 8 \\ \text { las coronas de los reyes } & 8 \\ \text { y los cetros imperiales } & 8 \\ \text { y refulge en los altares } & 8 \\ \text { y sostiene al Dios eterno } & 8 \\ \text { en las custodias radiantes } & 8\end{array}$
décimo:

El párrafo quinto presenta un ritmo endecasilábico indudable, que se repite en el

Cantemos el oro, porque su voz es música encantada; porque es heroico y luce en las corazas de los héroes homéricos, y en las sandalias de las diosas y en los coturnos trágicos y en las manzanas del jardín de las Hespérides.

$\begin{array}{ll}\text { porque su voz es música encantada; } & 11 \\ \text { porque es heroico y luce en las corazas } & 11 \\ \text { de los héroes homéricos, } & 7 \\ \text { y en las sandalias de las diosas } & 9 \\ \text { y en los coturnos trágicos } & 7 \\ \text { y en las manzanas del jardín } & 9 \\ \text { de las Hespérides. } & 5\end{array}$

Junto a esta segmentación que proponemos son admisibles otras variantes que cumplen también el ritmo endecasilábico. Al final del himno del poeta-mendigo, encontramos otro párrafo imbuido de metros:

¡Eh, miserables, beodos, pobres de solemnidad, prostitutas, mendigos, vagos, ratero, bandidos, pordioseros, peregrinos, y vosotros desterrados, y vosotros holgazanes, y sobre todo, vosotros, oh poetas!

$\begin{array}{ll}\text { ¡Eh, miserables, beodos, } & \mathbf{8} \\ \text { pobres de solemnidad, } & 8 \\ \text { prostitutas, } & 4 \\ \text { mendigos, vagos, rateros, } & 8 \\ \text { bandidos, pordioseros, } & 8 \\ \text { peregrinos, } & 4 \\ \text { y vosotros los desterrados, } & 9 \\ \text { y vosotros los holgazanes, } & 9 \\ \text { y sobre todo, vosotros, } & \mathbf{8} \\ \text { oh poetas! } & 4\end{array}$

El párrafo comienza por dos octosílabos seguidos por un pie quebrado, estructura que se repite. Para evitar el ritmo versal demasiado evidente, Rubén Darío introduce a continuación dos eneasílabos consecutivos con el mismo molde sintáctico y la misma acentuación ( $3^{\mathrm{a}}$ y $8^{\mathrm{a}}$ sílabas), para terminar retomando el ritmo inicial con un octosílabo $y$ un pie quebrado. 
Así pues, parece evidente que «La canción del oro» no basa su ritmo solamente en los procedimientos prosarios del paralelismo, la antítesis y la enumeración, sino que los ritmos versales (de cláusulas $\mathrm{y}$, principalmente, silábicos) son perceptibles a lo largo de la composición.

Ahora bien, no faltan estudios que han señalado las formas híbridas entre el verso y la prosa. En este sentido, «El país del sol», composición fechada en 1893 e incluida en Prosas profanas, ha recibido la atención de los estudiosos (cf. Domínguez Caparrós, 1999: 200). Isabel Paraíso señala la recurrencia continua al paralelismo y a la rima. Resalta el hecho de que el estribillo se separa tipográficamente «como en un poema en verso"; y enumera las similicadencias, los numerosos metricismos y cláusulas dactílicas. Pero nos advierte que «en el interior de los párrafos, las disritmias se suceden y la impresión de prosa domina» (Paraíso, 1985: 108). La conclusión de Paraíso es que se trata de un experimento formal en el que se mezclan verso y prosa, para crear una forma híbrida a la que denomina versículo mayor. La recepción de esta forma híbrida, según Paraíso, habría sufrido una evolución: «Esta forma de versículo mayor, para nosotros hoy verso libre ya, la forma del verso libre que limita con la prosa (con el poema en prosa), era percibida por Rubén y sus contemporáneos como prósica, no versal» (Paraíso, 1985: 112) ${ }^{12}$.

La posición de Utrera con respecto a la clasificación genérica de «El país del sol» sigue la línea de Paraíso, aunque insistiendo en el componente rítmico regular: «se trata de prosa ritmada y rimada en la que es perceptible la penetración del verso. [...] el poeta se deja llevar por una casi total regularidad rítmica que acerca el poema a la modalidad musical del poema en prosa parnasiano y simbolista y, más concretamente, a los experimentos franceses finiseculares que en un nuevo tipo de poema conjugan prosa rítmica y verso» (Utrera, 1999: 246). A pesar de considerarlo prosa, Utrera no duda en resaltar los componentes versales de la composición: «El predominio del ritmo endecasilábico está marcado a menudo por el juego de la rima que permite separar en esta artificiosa composición los grupos silábicos que bien podrían presentarse como verso en otras clase de disposición tipográfica sin perder su condición experimental. El acercamiento entre verso y prosa no es sino resultado de la teoría poética dariana que busca la musicalidad y el ritmo del verso absoluto» (Utrera, 1999: 247). Con estos presupuestos, se comprende que Utrera considere que la confusión genérica explica que este tipo de composiciones sean difícilmente clasificables, «puesto que obedecen a una continua tensión entre los dos modos rítmicos del verso y de la prosa» (Utrera, 1999: 247).

Por último, debemos anotar que Ruben Darío llegó a «prosificar» uno de los poema en verso de Cantos de vida y esperanza, el titulado «Cleopompo y Heliodemo», "probablemente por la urgencia de un compromiso ya contraído» (Utrera, 1999: 249). Al margen de ese hipotético compromiso al que se refiere Utrera, Rubén Darío pudo realizar ese proceso en la medida en que como poeta concebía que el ritmo versal podía introducirse en la prosa. Además Rubén Darío no dejaría de ser consciente de la diferencia de sentimientos rítmicos que produciría su presentación como verso o como prosa; el principio de la composición es el siguiente:

\footnotetext{
12 Paraíso había ya tratado el problema de la penetración de ritmos versales (cuantitativo y acentual) en algunos poemas en prosa, como «la canción de la Esfinge rechazada» de Miguel Melendres y «Hablemos seriamente» de Rafael Santos Torroella, con predominio del ritmo heptasilábico (Paraíso, 1976: 89-101).
} 
Cleopompo y Heliodemo, cuya filosofía es idéntica, gustan dialogar bajo el verde palio del platanar. Allí Cleopompo muerde la manzana epicúrea y Heliodemo fía al aire su confianza en la eterna harmonía.

Cleopompo y Heliodemo, cuya filosofía

Es idéntica, gustan dialogar bajo el verde

Palio del platanar. Allí Cleopompo muerde

La manzana epicúrea y Heliodemo fía

$\mathrm{Al}$ aire su confianza en la eterna harmonía.

Quizá nuestro distinto sentimiento rítmico frente a las dos presentaciones se deba a los encabalgamientos. Volvemos a encontrar la presentación como prosa de poemas preexistentes en las obras de Unamuno y, sobre todo, en la última etapa de Juan Ramón Jiménez.

\section{6. 'ClLARIN' Y EL POEMA EN PROSA}

Sin embargo, la introducción en España del poema en prosa no estuvo exenta de polémicas literarias entre los defensores de las posiciones más tradicionalista (Campoamor, Núñez de Arce), que defendían la separación genérica estricta, y los adelantados de las nuevas corrientes literarias ('Clarín', Varela), en gran medida, procedentes de Europa. González Ollé (1964) dedicó un interesante artículo a analizar una colaboración de 'Clarín' titulada «Pequeños poemas en prosa. Prólogo» que se publicó el 15 de mayo de 1888 en la Revista del Antiguo Reino de Navarra. Se trata en realidad de un ensayo de teoría literaria bajo la forma de alegoría y con un tono humorístico bastante marcado ${ }^{13}$. 'Clarín' se plantea la posibilidad de componer poemas en prosa, es decir, sin metro ni rima, siguiendo el ejemplo de Baudelaire. Pide disculpas a las dos glorias líricas del momento, Campoamor y Núñez de Arce, por invadir un terreno ajeno; ahora bien, su prosa poética futura nada tendrá que ver con la poesía prosaica de Campoamor. En palabras de 'Clarín':

Campoamor, si se lo juro, me creerá que yo podría también imitarle, y hacer endecasílabos en prosa, como los tristes epigones de la poesía prosaica (apud González Ollé, 1964: 50).

'Clarín' alegoriza la expresión literaria bajo la imagen de un ejército: la poesía versificada es el ejército desfilando deslumbrante y espectacular en su partida; la «prosa prosaica» es el ejército en campaña que abandona toda formación para marchar por terrenos abruptos y cubierto por el polvo; «la poesía en prosa es el ejército victorioso: las filas se rompen por las necesidades de la lucha y no se percibe sensiblemente ningún ritmo en los movimientos de los combatientes. Pero ese ritmo existe, invisible, en la mente que dirige la batalla y, gracias a él, se vence» (González Ollé, 1964: 57). Para 'Clarín' la prosa poética no se somete ni a la rima ni al ritmo del verso; está dotada de un ritmo propio de índole intelectual, que 'Clarín' no acierta a definir.

${ }^{13}$ Tampoco faltan notas satíricas sobre escritores del momento. 
Paralelamente a la defensa del poema en prosa, 'Clarín' expone su teoría sobre la superioridad de la prosa sobre el verso. Su base argumentativa está en la superioridad de las bellezas naturales sobre las bellezas del arte; las bellezas naturales se expresan mejor en prosa, que es la forma de expresión más espontánea y natural. Por el contrario, el verso, como la música, somete a la naturaleza según las prescripciones formales (González Ollé, 1964: 57). Finalmente, 'Clarín' trata de la imitación artística mediante una pequeña fábula, en la que repite que la prosa es copia o reflejo fiel de la belleza natural, mientras que el verso en vez de reflejar canta esa misma belleza. González Ollé (1964: 58) hace notar que toda esta teoría parte de presupuestos naturalistas y resumen su análisis con estas palabras: «La conclusión final a que puede llegarse es la de que 'Clarín' preconiza el poema en prosa, pero consciente de la innovación que suponía en el panorama literario del momento, de las repulsas que iba suscitar, expone sus ideas sobre la cuestión en un tono enigmático y humorístico que amortigua las afirmaciones y desdibuja su perfil hiriente. Todo parece quedar reducido, para un lector poco atento, a una inofensiva broma literaria de confusa finalidad» (González Ollé, 1964: 59).

Sin embargo, no nos debe pasar desapercibido que en algunos pasajes de sus «Poemas en prosa» parece percibirse un intento de organizar rítmicamente la composición; González Ollé lo señala para los capítulos IV (con similitudes respecto a la «Marcha triunfal» de Rubén Darío) y IX. González Ollé sugiere que la defensa del poema en prosa y una hipotética práctica de ese género por 'Clarín', están motivadas por su juvenil vocación poética. El limitado talento para los versos empujó a 'Clarín' a cultivar el cuento y, en general, la prosa (González Ollé, 1964: 60-61) e hipotéticamente al poema en prosa. De ahí que vicariamente el personaje de Ana Ozores, después de superar una crisis anímica y de salud, recurra a ese género y componer un himno de «versos en prosa» (González Ollé, 1964: 61). Quizá cabría transcribir ahora algunas estrofas de un poema irónico y autoirónico, citado por González Olle (1964, 60-61).

Los pocos versos que hice eran fríos, abstractos y premiosos, de un profano, producto al fin, de olímpicos desvíos.

Por eso los quemé; y en castellano que procuro pulir, escribo en prosa, libre de ripios y en estilo llano.

[...]

No tengo lira, al menos no la toco; pero tengo unos bosques y colinas donde sembré mis sueños locos. [...] Porque versificar es cosa brava; pero cabe también la poesía sin el run-rún de frase candenciosa.

En otro trabajo anterior, González Ollé da cuentas de la polémica que surgió en el último cuarto del s. XIX entre poesía y prosa. La posición más académica y tradicional, representada por Núñez de Arce, sale en defensa de la poesía, ridiculizando «tanto la 
prosa poética como la poesía prosaica» (González Ollé, 1963: 210). En su respuesta, 'Clarín' nos advierte de que algunas variedades prosísticas de la época participan de las características del verso y que la máxima indiferenciación de prosa y verso se alcanza con Flaubert y los simbolistas (González Ollé, 1963: 215). 'Clarín' justifica a los partidarios de la abolición del metro, lo que no significa la desaparición de la poesía. Y esta evolución lleva, según 'Clarín', a la prosa poética: «De toda esta doctrina literaria [de 'Clarín'], considero que el punto más importante, al menos históricamente, radica en la proclamación de la prosa poética» (González Ollé, 1963: 217) ) $^{14}$.

Frente a Núñez de Arce y Campoamor, 'Clarín' aparece como precursor de la literatura innovadora que superará el realismo y, de alguna manera, precursor del modernismo (González Ollé, 1963: 227). Junto a su conciencia de la evolución de la poesía, 'Clarín' toma partido por la prosa en su relación con el verso:

Sin la prosa $[\ldots]$ seríamos monos, $\boldsymbol{o}$ antropoides por lo menos [...]. La prosa y el verso no son dos especies de un mismo género, sino un género y una especie de éste. Comparar el verso con la prosa, es como comparar la música con el sonido. El sonido es el género, y la música la especie [...]. El verso bueno debe tener todas las cualidades de la prosa buena... más las suyas especiales. El verso no es más que un modo de la prosa [...], el modo rítmico (apud González Ollé, 1963: 214).

Si 'Clarín' identifica el lenguaje humano con la prosa y, por tanto, el verso sólo es la modalidad rítmica del lenguaje-prosa, Juan Ramón Jiménez adopta una concepción opuesta: toda expresión estética del lenguaje humano debe partir del ritmo y, por tanto, es verso, independientemente de su presentación tipográfica. En los debates literarios de fin del siglo XIX, la polémica en torno al poema en prosa y la prosa poética tiene una importancia capital, según nos señala González Ollé (1964: 65). En esa época se produciría tanto un acercamiento de la prosa al verso, como del verso a la prosa. González Ollé cita unas expresivas palabras de Campoamor:

Así como hay que bajar el diapasón en la poesía, es necesario subir el de la prosa $[\ldots]$. Democratizar mucho la poesía y aristocratizar un poco más la prosa, es un trabajo digno de alguno de los escritores que nos sucedan y que tengan bastantes fuerzas para palanquear el idioma (apud González Ollé, 1964: 66).

Según González Ollé, Campoamor llevó a cabo la primera parte de esta propuesta. El desarrollo del poema en prosa y de la prosa poética era la segunda. Ya antes había apuntado este fenómeno Baquero Goyanes (1949: 197), al afirmar que los modernistas intentaron acercar la prosa al verso, simétricamente al intento de Campoamor y Núñez de Arce con respecto a la poesía. En todo caso, 'Clarín' mantuvo el principio antimétrico para explicar las complejas relaciones de verso y prosa.

\footnotetext{
${ }^{14}$ En este debate literario, «Campoamor no se muestra muy original en lo referente a las relaciones entre prosa y verso. Su posición le sitúa en una línea tradicional de distinción radical entre ambas modalidades expresivas, hostil a formas nuevas como la prosa poéticà (González Ollé. 1963: 225).
} 


\section{Cernuda y Borges}

Como vimos en el parágrafo $\S 1$, Cernuda, en su ensayo sobre el poema en prosa, considera que en las Leyendas Bécquer utilizó, a excepción del verso, todos los recursos literarios de la poesía (Cernuda, 1975: 988-989). La prosa del poema en prosa y la poesía comparten acento, ritmo y estilo de expresión, pero se excluye la posibilidad de que el poema en prosa pueda segmentarse rítmicamente como lo hace el verso. Veíamos que renacía así el principio antimétrico en la crítica cernudiana. La contradicción entre las posturas críticas y la práctica real de la prosa rítmica cobra en el caso de Cernuda una intensidad mayor, puesto que como crítico adopta la posición axiomática de la tradición pero como escritor de poemas en prosa con frecuencia utiliza recursos propios de la versificación. De esta manera, podemos comprobar que en su práctica literaria Cernuda no siguió siempre el principio antimétrico - al que se adhiere sin reservas como críticotendente a separar verso y prosa. Analicemos el principio del poema en prosa titulado «El miedo» (Ocnos):

Por el camino solitario, sus orillas sembradas de chumberas y algún que otro eucalipto, al trote de las mulas del coche, volvía el niño a la ciudad desde aquel pueblecillo con nombre árabe. ¿Cuántos años tendría entonces: cinco o seis? (Cernuda, 1975: 25).

La sensación de estar oyendo en este fragmento de prosa un ritmo conocido es evidente; no es otra cosa que el universal ritmo endecasilábico que fundamenta la poesía culta contemporánea y, concretamente, toda la poesía de Cernuda desde la postguerra. La segmentación rítmica lo deja patente:

$\begin{array}{ll}\text { Por el camino solitario, } & 9 \\ \text { sus orillas sembradas de chumberas } & 11 \\ \text { y algún que otro eucalipto, } & 7 \\ \text { al trote de las mulas del coche, } & 10 \\ \text { volvía el niño a la ciudad } & 9 \\ \text { desde aquel pueblecillo } & 7 \\ \text { con nombre árabe. } & 5 \\ \text { ¿Cuántos años tendría entonces: cinco o seis? } & 11 \\ \text { (Cernuda, 1975: 25). } & \end{array}$

El ritmo endecasilábico se rompe en «al trote de las mulas del coche», pero no es menos cierto que podríamos estar ante un caso similar a la "sinafía». La utilización del ritmo endecasilábico en la prosa se remonta al mismo momento en que nace el verso libre de ritmo endecasilábico. La mayor parte de la crítica considera que casos como los de las composiciones «Galicia» $\mathrm{y}$ «Las estradas de Albia» de Unamuno, incluidas en Andanzas y visiones españolas, o los numerosos poemas de la última etapa de Juan Ramón Jiménez son en realidad un proceso de prosificación tipográfica (Devoto, 1984: 34; y Paraíso, 1985: 184): se trataría de verdaderos poemas escritos en verso libre y presentados como prosa. El fenómeno es demasiado complejo y abordarlo adecuadamente requiere un trabajo monográfico, ya en curso de realización. 
Sin embargo, podemos considerar un caso más claro. Jorge Luis Borges publicó en 1985 Los conjurados, libro que combina poemas en verso y poemas en prosa y al que no se le puede atribuir ningún afán experimental (sobre todo si tenemos en cuenta que Rubén Darío publicó Azul un siglo antes). En Los conjurados, no hay ningún indicio que nos haga sospechar que se ha producido algún tipo de prosificación al modo de Juan Ramón Jiménez o de presentación tipográfica de los poemas escritos en verso libre como prosa al modo de Unamuno. Ahora bien, cuando se lee la «Inscripción» que abre la obra, se siente un ritmo similar al de los poemas escritos en verso libre, desde su párrafo inicial al último:

Escribir un poema es ensayar una magia menor. El instrumento de esa magia, el lenguaje, es asaz misterioso. Nada sabemos de su origen. Sólo sabemos que se ramifica en idiomas...

Sólo podemos dar lo que ya hemos dado. Sólo podemos dar lo que ya es del otro. En este libro están las cosas que siempre fueron tuyas. ¿Qué misterio es una dedicatoria, una entrega de símbolos!

La sensación se confirma cuando segmentamos rítmicamente estos fragmentos:

Escribir un poema

es ensayar una magia menor.

El instrumento de esa magia,

el lenguaje, es asaz misterioso.

Nada sabemos de su origen.

Sólo sabemos

que se ramifica en idiomas...

Sólo podemos dar lo que ya hemos dado.

Sólo podemos dar lo que ya es del otro.

En este libro están las cosas

que siempre fueron tuyas.

¡Qué misterio es una dedicatoria, una entrega de símbolos!
7

11

9

11

9

5

9

$7+7$

$7+7$

9

7

11

7

El mismo ritmo endecasilábico que sustenta los poemas escritos en verso libre subyace en no pocas de las composiciones en prosa de Los conjurados de Borges.

\section{CONCLUSIÓN}

Las relaciones históricas de la prosa artística con el verso, desde la oratoria griega hasta el moderno poema en prosa, se sustentan dialécticamente en el ideal del cumplimiento del principio antimétrico y en su inevitable ruptura. El objetivo de infundir ritmo a la prosa al margen del sistema de versificación coetáneo se señala explícitamente en los tratados teóricos, desde Aristóteles a nuestros días. Ahora bien, los textos en prosa, 
desde Isócrates a Borges, no sólo utilizan los recursos de pensamiento (paralelismos y antítesis), sino también los procedimientos rítmicos propios del sistema de versificación.

Junto a composiciones como «El caudillo de las Manos Rojas» de Bécquer y «Elegía» de Somoza, hemos analizado un caso muy significativo, «La canción del oro» de Rubén Darío. Este «himno en prosa» presenta similitudes con la versificación de cláusulas; el octosílabo y su pie quebrado; y la versificación basada en en endecasílabo. Por último, debemos recordar que en Los conjurados de Borges alternan verso libre y prosa, y que ambos modos de composición responden al ritmo endecasilábico.

Después de recoger estos datos empíricos, no parece arriesgado concluir que, como ha señalado Domínguez Caparrós (1988a), la prosa sólo se distingue del verso por tres rasgos: la ausencia de patrón rítmico; el carácter progresivo de su ritmo; y la disposición gráfica. De esta manera, el poema en prosa puede incluir series de segmentos rítmicos coincidentes con versos, pero su ritmo carece de patrón rítmico preestablecido. El poema en prosa adopta la disposición tipográfica de la prosa como expresión de la voluntad rítmica del autor y del carácter progresivo de su ritmo.

\section{REFERENCIAS BIBLIOGRÁFICAS}

AUllón DE HARO, P. (1979) «Ensayo sobre la aparición y desarrollo del poema en prosa en la literatura española», Analecta Malacitana 2, 109-136.

BERnABE, A. (1998) Aristóteles. Retórica, Madrid: Alianza.

BreItenBaCh, H.P. (1911) «The De Compositione of Dionysius of Halicarnassus considered with reference to the Rhetoric of Aristotle», CPh 6, 163-179.

Cernuda, L. (1975) «Bécquer y el poema en prosa español», en Prosa completa, Barcelona: Seix Barral, 984-993.

Díaz Plaja, G. (1956) El poema en prosa en España, Barcelona: Gustavo Gili.

Devoto, D. (1980-1982): "Leves o aleves consideraciones sobre lo que es el verso", Cahiers de Linguistique Hispanique Médiévale 5, 67-100; 7, 5-60.

Devoto, D. (1984) «Prosa con faldas», Edad de Oro 3, 33-65.

Dominguez Caparrós, J. (1988a) «Prosa y verso», en Métrica y Poética. Bases para la fundamentación de la Métrica en la Teoría Literaria Moderna, Madrid: UNED, 21-30.

DOMfNGuEz CAPARRós, J. (1988b) Contribución a la bibliografia de los últimos treinta años sobre la métrica española, Madrid: CSIC.

Dominguez Caparrós, J. (1990) “Métrica y poética en Rubén Darío», en VV. AA., El Modernismo. Renovación de los lenguajes poéticos, Valladolid: Universidad, 31-46.

DOMINGUEZ CAPARRós, J. (1993) Métrica española, Madrid: Síntesis.

DOMfNGUEZ CAPARRós, J. (1999) «El modernismo en la formación del verso español contemporáneo", en J. Domínguez Caparrós Estudios de Métrica, 181 -207.

DOMínguez CaParrós, J. (1999) Estudios de métrica, Madrid: UNED.

Galán Vioque, G. y MÁrQuez, M.A. (2001) Dionisio de Halicarnaso. Sobre la composición literaria, y otras obras, Madrid: Gredos.

LAUSBERg, H. (1966) Manual de retórica literaria. Fundamentos de una ciencia de la literatura I-III, Madrid: Gredos.

Márquez, M. A. (2000) «El versículo en el verso libre de ritmo endecasilábico», Bulletin of Hispanic Studies LXXVII, 217-234. 
Márquez Guerrero, M. (2001) «La rima en la poesía última de Vicente Aleixandre», Hispanic Review 69, 337-353.

NúÑEZ GONZÁLEZ, J.M. (1988) «El numerus oratorius. Panorama de sus principales problemas y métodos», en Estudios de drama y retórica en Grecia y Roma, G. Morocho (ed.), León: Universidad, 305-321.

Paraíso, I. (1976) Teoría del ritmo en la prosa, Barcelona: Planeta.

Parafso, I. (1985) El verso libre hispánico. Origenes y corrientes, Madrid: Gredos.

Paraíso, I. (2000) La métrica española en su contexto románico, Madrid: Arco/Libros.

RACIONERo, Q. (1994) Aristóteles. Retórica, Madrid: Gredos.

SÁNCHEZ SALOR, E. (1991) Cicerón. El orador, Madrid: Alianza.

TORRE, E. (1999) El ritmo del verso, Murcia: Universidad.

TORRE, E. (2000) Métrica española y comparada, Sevilla: Universidad.

Utrera Torremocha, M.V. (1999) Teoría del poema en prosa, Sevilla: Universidad de Sevilla. VALENDER, JAMES (1984) Cernuda y el poema en prosa, Londres: Támesis Books. 